Check for updates

Cite this: RSC Adv., 2018, 8, 21020

\title{
Green synthesis of Pd nanoparticles supported on reduced graphene oxide, using the extract of Rosa canina fruit, and their use as recyclable and heterogeneous nanocatalysts for the degradation of dye pollutants in water
}

\author{
Saba Hemmati, ${ }^{\text {*a }}$ Lida Mehrazin, ${ }^{\mathrm{b}}$ Hedieh Ghorban, ${ }^{\mathrm{b}}$ Samir Hossein Garakani, ${ }^{\mathrm{b}}$ \\ Taha Hashemi Mobaraki, ${ }^{b}$ Pourya Mohammadi and Hojat Veisi (DD *a \\ The current study suggests a convenient synthesis of in situ, ecofriendly and well-dispersed palladium \\ nanoparticles with narrow and small dimension distributions on a graphene oxide (GO) surface using \\ a Rosa canina fruit extract as a stabilizer and reducing agent without the addition of any other stabilizers \\ or surfactants. The as-synthesized nanocatalyst (Pd NPs/RGO) was assessed with XRD, UV-vis, FE-SEM, \\ EDS, TEM, ICP and WDX. The obtained heterogeneous nanocatalyst showed catalytic performance for \\ reducing 4-nitrophenol (4-NP), rhodamine $B(R h B)$ and methylene blue (MB) at ambient temperature in \\ an ecofriendly medium. The catalyst was retained by centrifugation and reused several times with no \\ considerable change in its catalytic performance.
}

Received 20th April 2018 Accepted 26th May 2018

DOI: $10.1039 / \mathrm{c} 8 \mathrm{ra03404d}$

rsc.li/rsc-advances extensively used in the nanoparticle form. Moreover, without difficulty, nanocatalysts can be removed from the products in a reaction mixture, and this creates recyclable catalysts. ${ }^{8 c-e}$

Among diverse m-NPs, Pd NPs have recently attracted much attention due to their abilities to be used as homogeneous or heterogeneous catalysts in different reactions due to their large surface to volume ratio. ${ }^{8 a-e, 13}$ However, the agglomeration of $\mathrm{m}$ NPs is unavoidable. An ideal support would be necessary to avoid this m-NPs agglomeration and would aid with the recovery, separation, and stability problems of m-NPs. Various inorganic compounds like $\mathrm{Ag},{ }^{15}$ graphene oxide, ${ }^{14} \mathrm{SiO}_{2},{ }^{17} \mathrm{TiO}_{2},{ }^{16}$ $\mathrm{Fe}_{3} \mathrm{O}_{4}$ (ref. 18) have been applied as supports for m-NPs. Among different solid supports, graphene and its derivatives are some of the best supports to grow and anchor m-NPs due to their great thermal stabilities, great specific surface areas, appropriate mechanical strengths, light weight properties, good conductivities and excellent adsorption capacities. ${ }^{19-21}$

There are various methods for the synthesis of m-NPs on graphene, reduced graphene oxide (RGO) and graphene oxide (GO) via chemical reduction (such as with sodium borohydride, hydrazine hydrate, salicylic acid, oxalic acid, ethylene glycol, $\mathrm{NaOH}$ and ascorbic acid) physical techniques, or metal precursors, etc. ${ }^{22}$ However, most of them need the application of hazardous chemicals, large amounts of energy, and are extremely expensive which would be unacceptable in the pharmaceutical, medicine and cosmetics industries. Reducing agents may cause harsh chemical absorption on the surfaces of NPs, improving the issues of toxicity. Thus, it is urgent to design a greener and better technique for the synthesis of m-NPs- 
graphene ( $\mathrm{GO}$ or/and $\mathrm{RGO}$ ) hybrids for the use in organic reactions as active catalysts. The green synthesis of m-NPs using non-toxic solvents like biological extracts, water, and environmentally benign techniques is considered as the most attractive

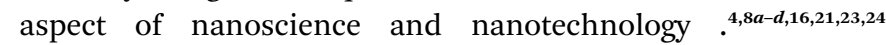
Furthermore, these methods have simple methodologies, easy work up and high yields, are cost-effective and environment friendly and have organic solvents removal advantages. Among the biological approaches, plant extract mediated biological procedures are useful and simple methods, with no use of costly, harsh and harmful chemicals, for the synthesis of different m-NPs that have been widely used for determining the presence of and removing ionic and dyes pollutants from aqueous media. ${ }^{8 a, 16,17}$ Biological approaches provide an alternative to common physical and chemical methods. ${ }^{4,8 a, c, d, 16,21,23,24}$

Researchers, up to now, have mainly focused on the application of biowaste materials as supports. The biowaste's low price make it a cheap adsorbent and catalyst support.

The genus Rosa, with more than 100 types, is extensively spread in the Middle-East, Asia, Europe and America. ${ }^{8 a, 25}$ Mature Rosa canina fruit (dog rose) (Fig. 1) has various biologically active compounds, such as organic acids, tocopherol, sugars, amino acids, pectins, fatty acids, flavonoids, tannins, vitamins (particularly vitamin $\mathrm{C}$ and other $\mathrm{K}, \mathrm{B} 1, \mathrm{~B} 2, \mathrm{PP}, \mathrm{D}$ and $\mathrm{E}$ vitamins), carotenoids (lycopene and $\beta$-carotene), micro- and macroelements, etc. These compounds are found to have antioxidant, anticancer and antimutagenic efficacy and constitute a crucial source of food and medicine for most civilizations. Routine food preparations of rose are jellies, jams, juices, wines and teas, as well as mixtures with caviar. ${ }^{8 a, 26,27}$ The latest research showed that extracts of Rosa canina fruit were influential for prevention of biofilm formation and inhibition of growth in methicillinresistant Staphylococcus aureus. The reaction of Rosa with biological molecules causes cell and tissue injuries by lipo peroxidation, DNA degradation or proteolysis. ${ }^{28,29}$

Various physical and chemical methods including sonochemistry, electrochemistry, microwave irradiation, solid state reaction, quick precipitation, sol-gel and alcohothermal synthesis have been applied for Pd NP synthesis. ${ }^{30-32}$ However, these methods have some difficulties, including harsh reaction conditions, high temperatures, time-consuming reactions, and the application of costly, poisonous and dangerous stabilizers or capping agents to

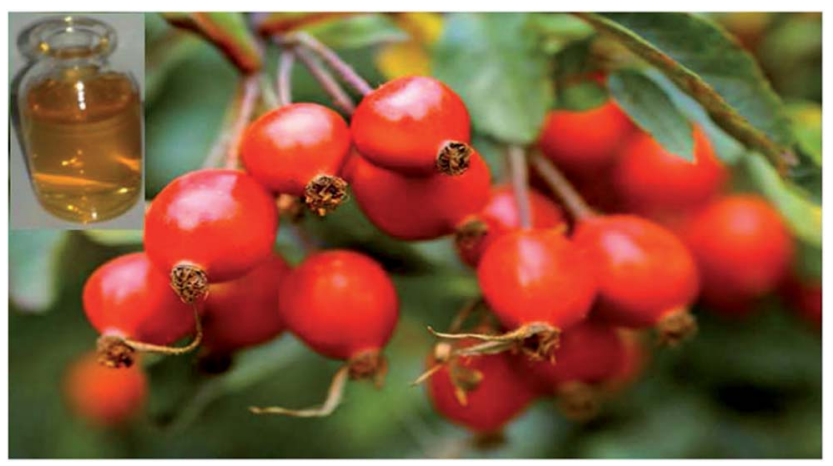

Fig. 1 Image of Rosa canina fruits. protect the dimensions and composition of the Pd NPs. The application of organic solvents and the low yields of products are causes of environmental pollution., ${ }^{4,8 c, 33-35}$ Among these methods, the green synthesis of NPs has benefits compared to other methods because of its easy reaction operation, being ecofriendly and cheap, having very mild reaction conditions, being suitable for large-scale fabrication, and the lack of a need to apply high temperatures or pressures, or use organic ligands, surfactants or costly and poisonous materials in the synthetic protocols. ${ }^{8 a, 23,24,36}$

Following our previously studies, ${ }^{37}$ here we report the synthesis of Pd NPs supported on reduced graphene oxide (Pd NPs/RGO) via the reduction of $\mathrm{Pd}^{2+}$ and GO ions by applying extracts of Rosa canina fruit as a stabilizing and reducing agent. The applied strategy provided well-dispersed Pd NPs on the graphene sheets. In addition, the main objectives of this study were to enhance the catalytic performance of the nanocatalyst and to recycle and reuse the nanocatalyst, with or without minimal degradation. The nanocatalyst was studied under mild operating conditions, for the degradation of organic dyes in water in the presence of $\mathrm{NaBH}_{4}$ at room temperature, by UV-vis spectroscopy.

\section{Experimental}

\subsection{Rosa canina fruit extract preparation}

The fresh Rosa canina fruits were thoroughly washed with double-distilled water three times before application. To $100 \mathrm{~mL}$ of deionized water, $10 \mathrm{~g}$ of fruit was added and for $15 \mathrm{~min}$ was boiled in a water bath. The mixture was then filtered and cooled down through Whatman filter paper no. 1 to achieve an aqueous extract. The filtered extract was stored in a refrigerator at $4{ }^{\circ} \mathrm{C}$ until required for further application.

\subsection{The Pd NPs/RGO green synthesis using Rosa canina extract}

Finally, using the aqueous Rosa canina fruit extract, the Pd NPs/ RGO was prepared. For the Pd NPs/RGO synthesis, the extract was added into GO, that was obtained from natural graphite powder, using a modified Hummers technique. ${ }^{38}$ Then, $50 \mathrm{~mL}$ of $0.3 \mathrm{M} \mathrm{PdCl}_{2}$ was added dropwise into the mixture at $80{ }^{\circ} \mathrm{C}$ under intensive stirring for $12 \mathrm{~h}$. By centrifugation, the achieved Pd NPs/RGO was separated from the reaction medium, and was washed with deionized water several times, and was then applied in the investigation and characterization of catalysis. The palladium concentration in Pd NPs/RGO was $12.6 \mathrm{wt} \%$, determined by ICP-AES.

\subsection{The general procedure for 4-NP reduction}

As an example, $10 \mathrm{~mL}$ of a solution of $2 \mathrm{mM}$ 4-nitrophenol was mixed with $2.0 \mathrm{mg}$ of the Pd NPs/RGO nanocomposite and the mixture was agitated for $1 \mathrm{~min}$ at ambient temperature. Next, $5 \mathrm{~mL}$ of a prepared $\mathrm{NaBH}_{4}$ solution $(0.25 \mathrm{M})$ was poured to the mixture and agitated at ambient temperature until the yellow solution became colorless. The progress of the reaction was recorded using UV-vis spectroscopy. After completion of reaction, the catalyst was isolated through centrifugation and was reused after washing with water and ethanol. 
2.4. Reduction of methylene blue (MB) and rhodamine $\mathrm{B}$ (RhB) by the Pd NPs/RGO nanocomposite

In general, $2.0 \mathrm{mg}$ of the nanocatalyst was poured into $10 \mathrm{~mL}$ of an aqueous solution of $\mathrm{MB}$ (or RhB) $\left(3 \times 10^{-5} \mathrm{M}\right)$. Next, $25 \mathrm{~mL}$ of aqueous $\mathrm{NaBH}_{4}\left(4 \times 10^{-3} \mathrm{M}\right)$ was poured into the mixture and the obtained mixture was agitated at ambient temperature. The development of the reaction conversion was examined through recording time-dependent UV-vis absorption spectra of the mixture with a spectrophotometer. After completion of the reaction, the catalyst was simply isolated from the reaction mixture using centrifugation, and was sequentially washed with ethanol and dried for the next cycle.

\section{Results and discussion}

\subsection{The results of catalyst characterization}

In this research, during one step, Pd NPs/RGO was prepared through the reduction of $\mathrm{Pd}^{2+}$ ions and graphene oxide using the extract of the Rosa canina fruit as a stabilizing and reducing

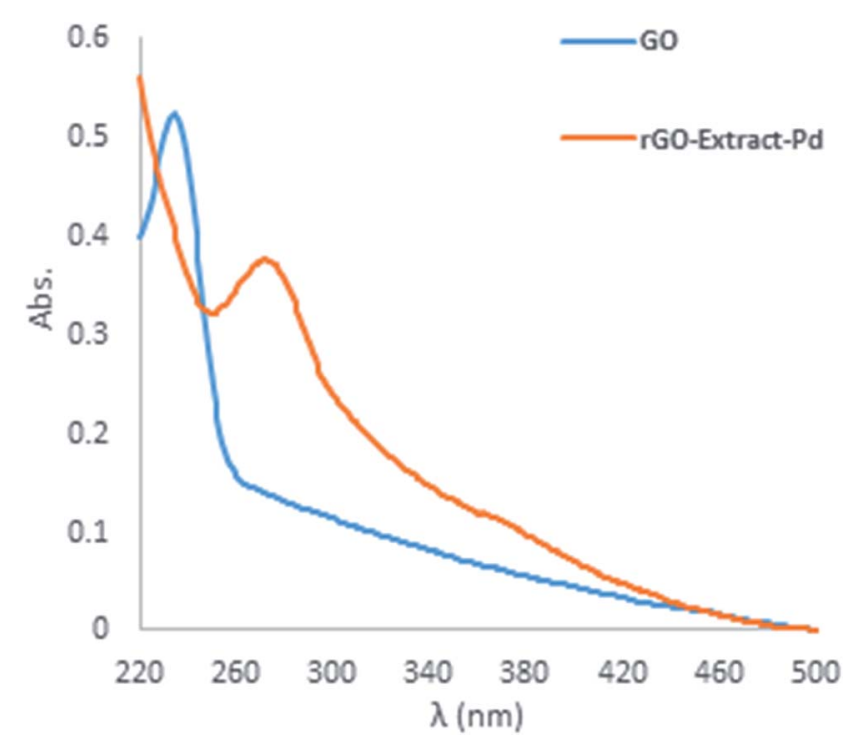

Fig. 2 UV-vis spectra of the GO and RGO. agent. The application of Rosa canina fruit extract, as a valuable and economic option, gave an environmentally benign and interesting synthetic route for Pd NPs without the application of hazardous materials and toxic organic solvents. The application of Rosa canina fruit extract as a green technique for Pd NPs synthesis was described in this study. ${ }^{8 a}$

Then, without using toxic, expensive, and harsh chemicals RGO was prepared from GO in the presence of Rosa canina fruit extract. The RGO was evaluated using UV-vis spectroscopy. The GO UV spectrum (Fig. 2) indicates a maximum absorption peak $\left(\lambda_{\text {max }}\right)$ at $232 \mathrm{~nm}$ because of the $\pi \rightarrow \pi^{*}$ transition of the aromatic $\mathrm{C}-\mathrm{C}$ bonds and a weak shoulder obtained at $300 \mathrm{~nm}$ because of the $\mathrm{n} \rightarrow \pi^{*}$ transitions of the $\mathrm{C}=\mathrm{O}$ bonds. The green RGO, that was synthesized using the Rosa canina fruit, gave a UV-vis spectrum with a new peak and a characteristic peak that red shifted from $232 \mathrm{~nm}$ to $270 \mathrm{~nm}$, showing the reaction end and the formation of RGO (Fig. 2).

At last, following this study, we applied the results to prepare Pd NPs/RGO by treating with $\mathrm{PdCl}_{2}$ and GO in Rosa canina fruit extract for $12 \mathrm{~h}$ at $80{ }^{\circ} \mathrm{C}$. The Pd NPs/RGO was evaluated by XRD, TEM, FE-SEM, DLS, WDX and EDS.

Fig. 3a and $\mathrm{b}$ show the results of the analysis of the field emission scanning electron microscopy (FE-SEM) performed to evaluate the morphology of GO and Pd NPs/RGO. Fig. $3 \mathrm{~b}$ is a FESEM representative image of the Pd NPs/RGO with large quantities of Pd NP distributed on the surface of the RGO in comparison with the GO. EDX analysis verified the elemental composition of the synthesized nanocomposite (Fig. 4). The strong peak at $3 \mathrm{keV}$ shows the existence of elemental $\mathrm{Pd}$ nanoparticles as was clear from previous observations. Apart from $\mathrm{Au}$, the other existing elements, shown by the EDX analysis, were carbon, nitrogen and oxygen.

Wavelength-dispersive X-ray spectroscopy (WDX)-coupled with quantified FE-SEM mapping of the sample was studied as well (Fig. 5). The wavelength-dispersive X-ray spectroscopy (WDX) can reveal qualitative data regarding the distribution of various chemical elements in the catalyst matrix. Considering the compositional maps of Pd and C of the Pd NPs, the existence of Pd and C, with suitable dispersion, is evidently characterized in the composite.
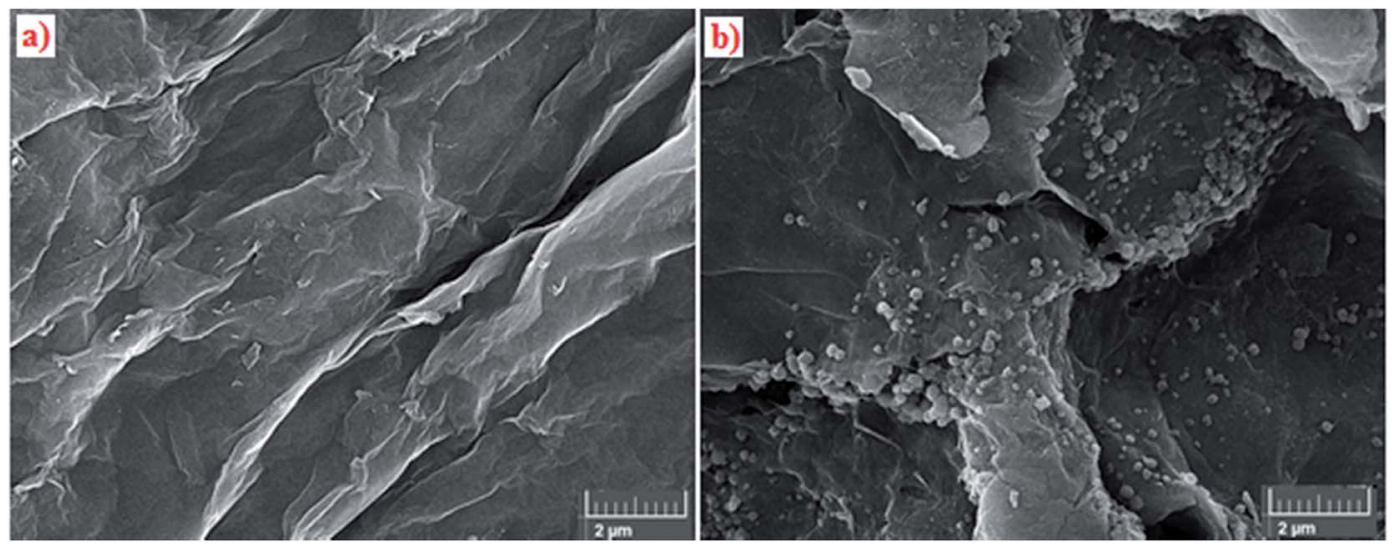

Fig. 3 (a) FE-SEM images of GO, and (b) Pd NPs/RGO. 


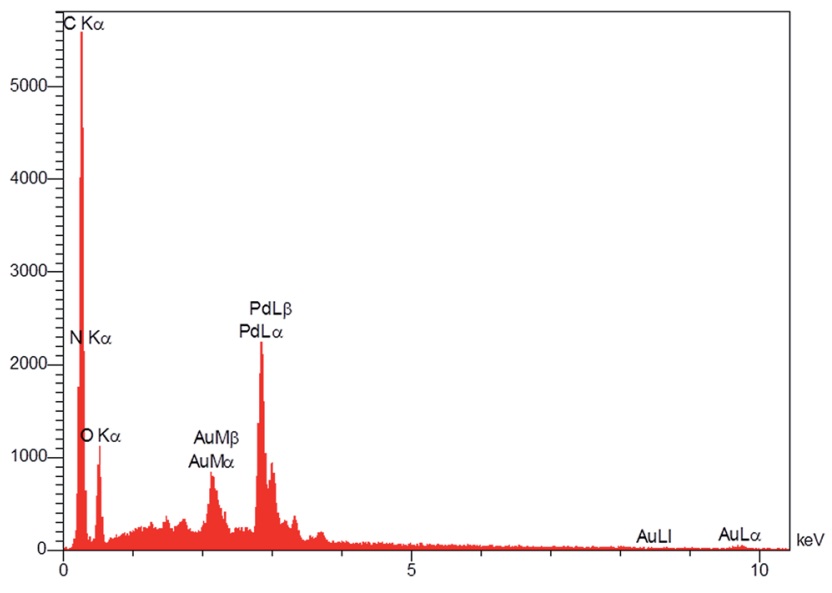

Fig. 4 EDX spectrum of Pd NPs/RGO.

Based on TEM analysis (Fig. 6), Pd was well-dispersed on the reduced GO surface. This outcome presented that the Rosa canina fruit extract has a main role in increasing the dispersibility of the Pd NPs.

Fig. 7 indicates the Pd NP size distributions. The histogram and TEM images show that the average size of the Pd NPs is approximately $13.67 \mathrm{~nm}$.

The XRD pattern of the Pd NPs/RGO can be seen in Fig. 8. XRD analysis indicates a diffraction peak at $2 \theta$ of $23.4^{\circ},(002)$ relating to the RGO. The XRD pattern indicates major diffraction peaks at $39.7^{\circ}, 46.5^{\circ}, 67.3^{\circ}(2 \theta)$, which can be indexed to the (111), (200), and (220) planes of face-centered cubic Pd (JCPDS no. 89-4897).

XPS is a powerful technique for investigation of the electronic features of a species formed on a surface, such as the electron environment, the oxidation state, and the binding energies of the core electrons of a metal. Fig. 9 shows the XPS elemental survey scans of the surface of the Pd NPs/RGO catalyst. The peaks corresponding to oxygen, carbon, nitrogen, and palladium are clearly seen in this spectrum. Moreover, XPS analysis was carried out to determine the oxidation state of the Pd. In Fig. 9, the Pd binding energy of Pd NPs/RGO indicates

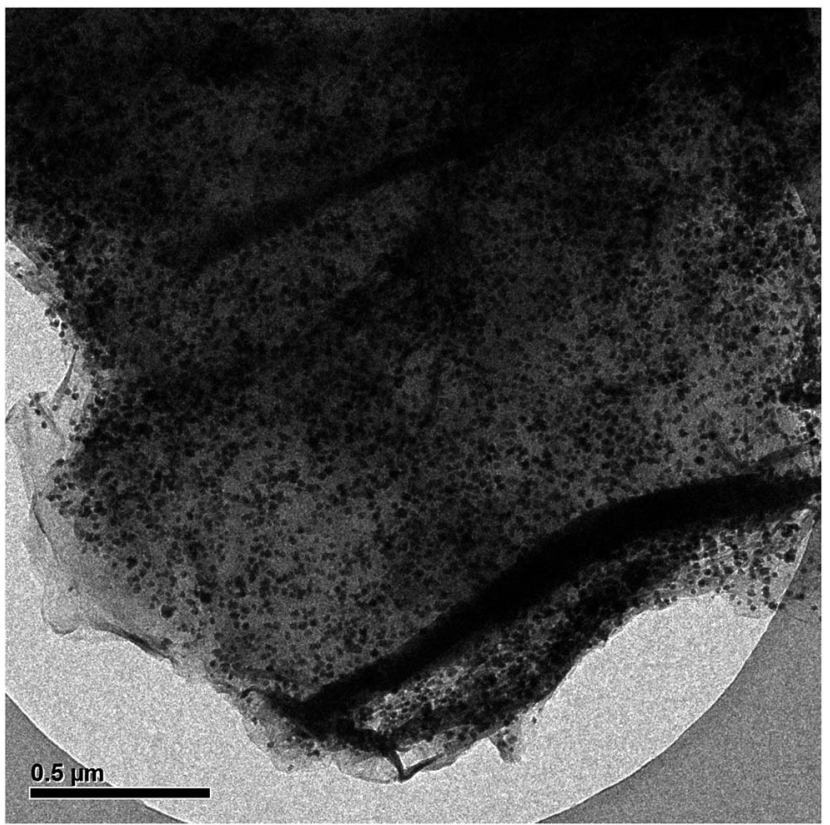

Fig. 6 TEM image of Pd NPs/RGO.

two peaks centered at 335.26 and $341.64 \mathrm{eV}$ relating to $\mathrm{Pd} 3 \mathrm{~d}_{3 / 2}$ and $\mathrm{Pd} 3 \mathrm{~d}_{5 / 2}$, respectively. According to earlier research, ${ }^{39}$ these peaks relate to $\operatorname{Pd}(0)$ species which are capped by groups of biomolecules from biological extracts. In other words, all Pd atoms are shown in their reduced form, which confirms the effective reduction of $\operatorname{Pd}(\mathrm{II})$ to $\mathrm{Pd}(0)$ NPs by the extract (Fig. 9, inset). The presence of $\mathrm{C} 1 \mathrm{~s}$ and $\mathrm{N} 1 \mathrm{~s}$ in the spectrum that resulted from XPS analysis reconfirmed the existence of the extract on the surface of the graphene.

\subsection{Application of Pd NPs/RGO for $p$-nitrophenol (4-NP), rhodamine $\mathrm{B}(\mathrm{RhB})$, and methylene blue (MB) catalytic} reduction

In order to investigate the catalytic performance of Pd NPs/RGO, the reduction of $p$-nitrophenol in the presence of $\mathrm{NaBH}_{4}$ was
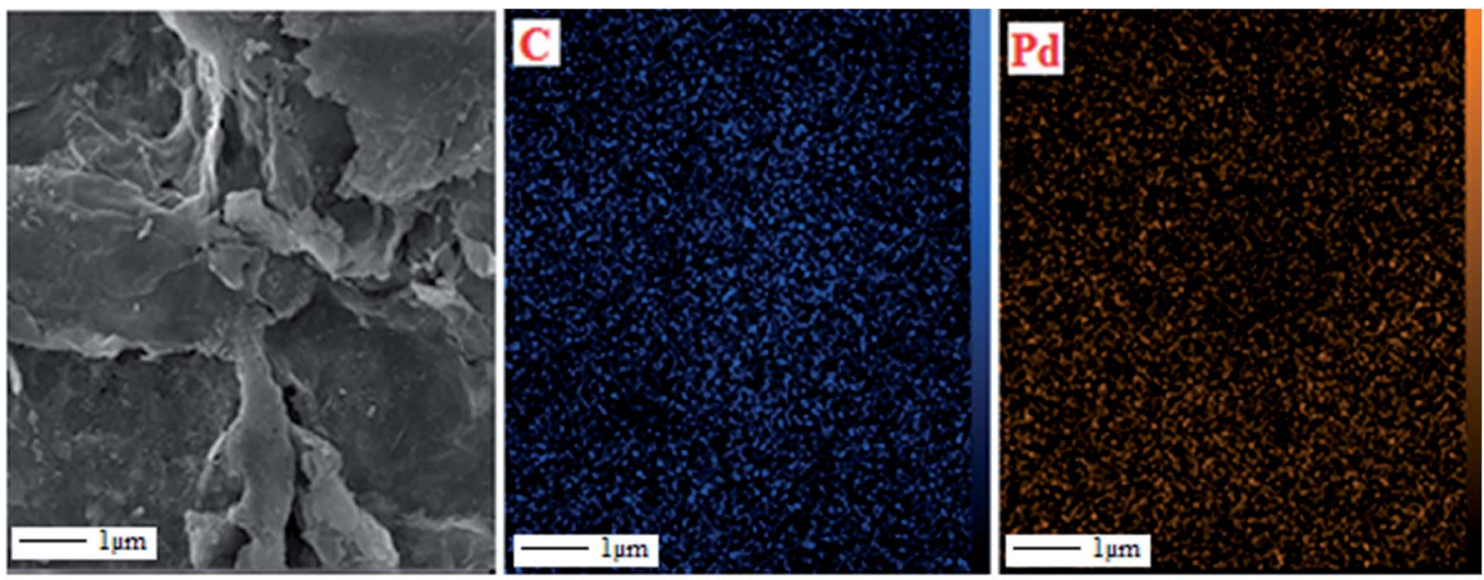

Fig. 5 FE-SEM image of Pd NPs/RGO and elemental maps of C, and Pd atoms. 

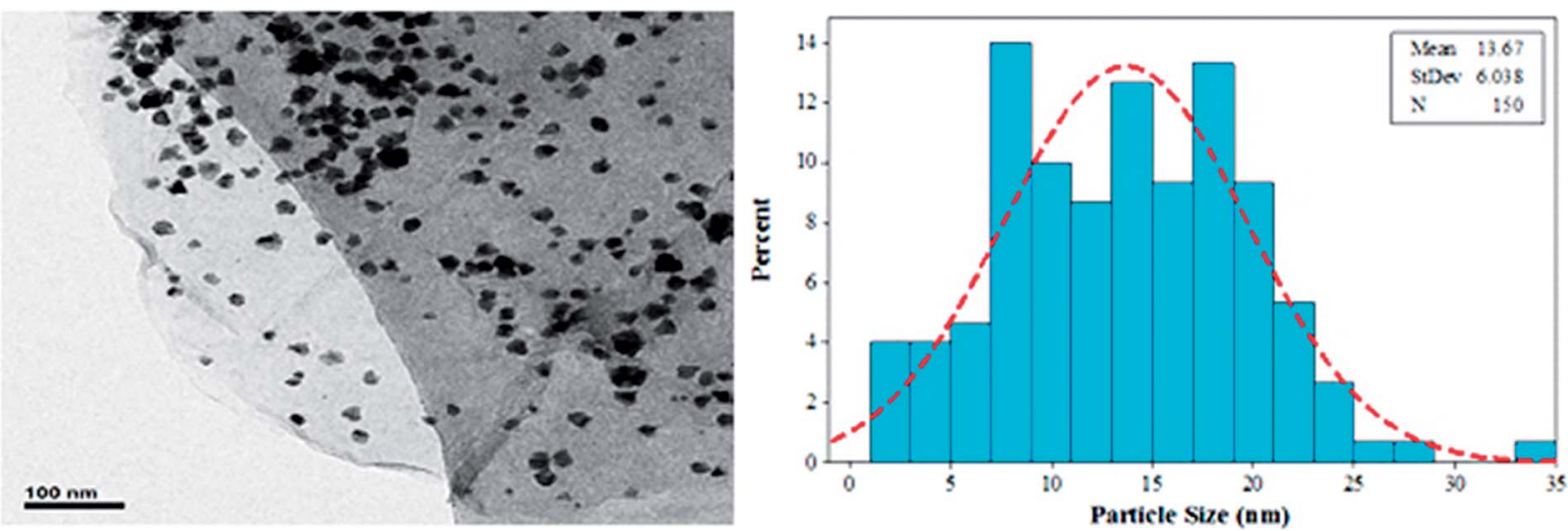

Fig. 7 TEM image of Pd NPs/RGO with Pd NP size distributions.

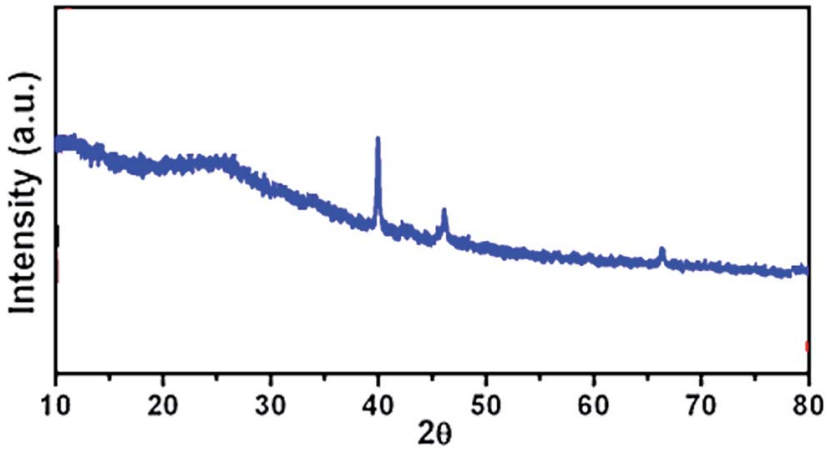

Fig. 8 XRD pattern of Pd NPs/RGO.

chosen as a model reaction for the reductions of rhodamine $\mathrm{B}$ (RhB), methylene blue (MB), and $p$-aminophenol.

3.2.1. 4-NP catalytic reduction. This reaction is especially simple to detect as there is just one product, $p$-aminophenol
(4-AP), and by change in the UV-vis absorbance measured at 300 and $400 \mathrm{~nm}$, the reaction extent can be followed. ${ }^{30,40}$ As shown in Fig. 10a, the absorption peak at $400 \mathrm{~nm}$ decreased significantly over $20 \mathrm{~s}$ and another peak was observed at $300 \mathrm{~nm}$ corresponding to 4-aminophenol. Consequently, it can be stated that 4-NP was completely converted to 4-aminophenol, indicating the reduction of 4-NP to the 4-AP form. The reduction happened from the donor, $\mathrm{BH}_{4}{ }^{-}$, to the acceptor, 4-NP, after the adsorption of both of them on the surface of the Pd/graphene NPs. A hydrogen atom formed from the hydride attack to reduce the molecules of 4-NP, following the electron transfer to the nanoparticles of Pd. ${ }^{4}$ The degree of reduction, catalyzed by Pd NPs/RGO, was considered to be affected by the $\mathrm{NaBH}_{4}$ level, as this reagent was used in great excess compared to 4-NP. Therefore, the kinetic data were fitted using a first-order rate law. Since the absorbance of 4-NP in the environment is proportional to its concentration, the ratio of absorbance at time $t\left(A_{t}\right)$ to that at the beginning of the reaction $\left(A_{0}\right)$ should be

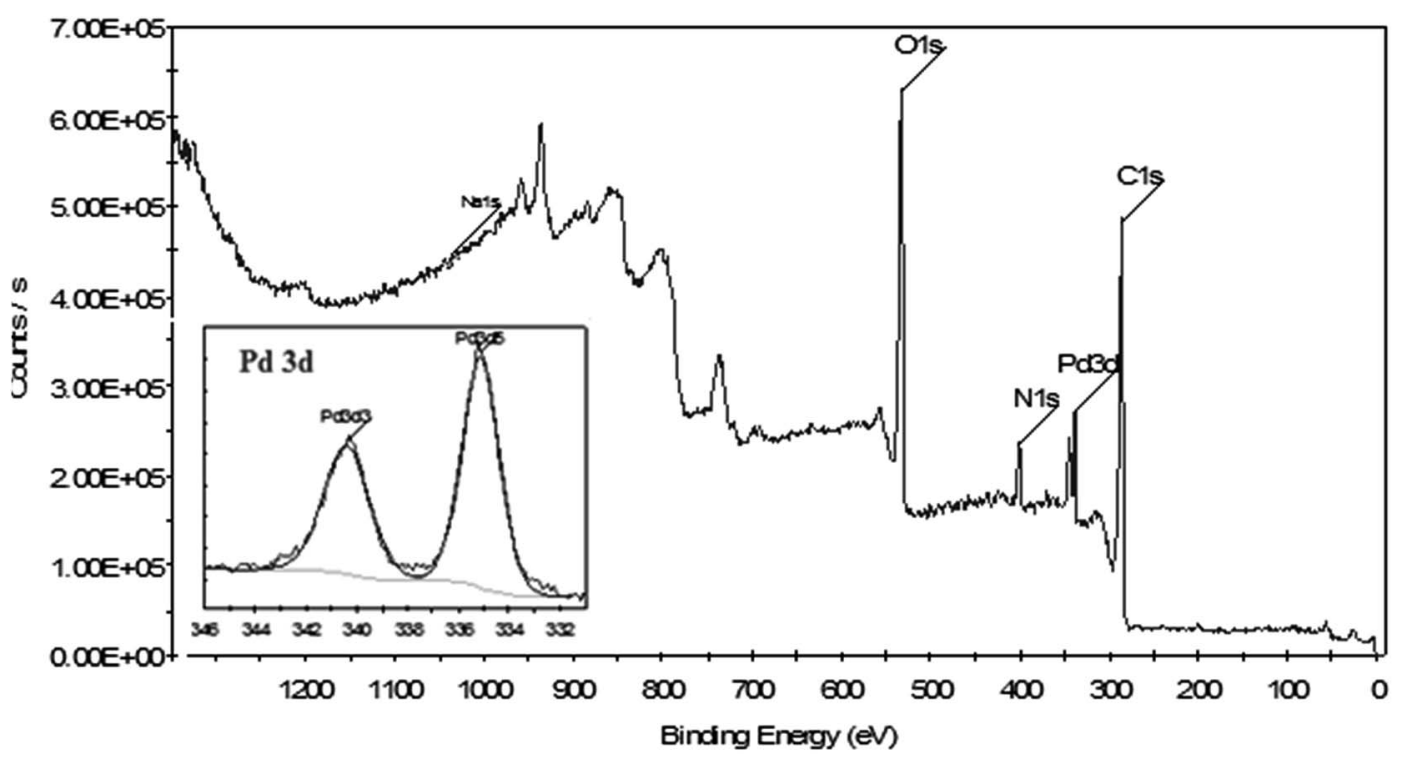

Fig. 9 XPS spectrum related to the elemental survey scan of Pd NPs/RGO and in the Pd $3 d$ region (inset). 

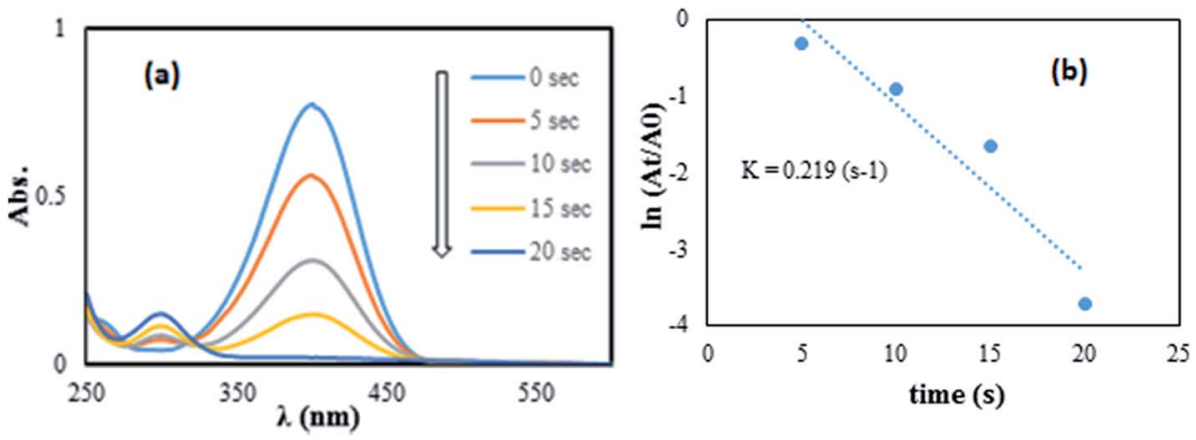

Fig. 10 The reduction of 4-NP in aqueous solution recorded every $5 \mathrm{~s}$ using the Pd NPs/RGO nanocomposite $(1 \mathrm{mg})$ as a catalyst (a) $\ln \left(A_{t} / A_{0}\right)$ versus reaction time for the reduction of 4-NP (b).

Table 1 Comparison of the results of this work with other reported methods in the reduction of 4-NP to 4-AP

\begin{tabular}{llll}
\hline Entry & Catalyst & Time & Ref. \\
\hline 1 & GA-Pt NPs & $8 \mathrm{~h}$ & 41 \\
2 & Resin-Au NPs & $20 \mathrm{~min}$ & 42 \\
3 & NAP-Mg-Au(0) & $7 \mathrm{~min}$ & 43 \\
4 & Ni-PVAm/SBA-15 & $85 \mathrm{~min}$ & 44 \\
5 & $\mathrm{Ag} \mathrm{NPs/seashell}$ & $4.5 \mathrm{~min}$ & 45 \\
6 & $\mathrm{Ag} / \mathrm{TiO}_{2}$ & $2 \mathrm{~min}$ & 16 \\
& nanocomposite & & \\
7 & PdCu/graphene & $1.5 \mathrm{~h}$ & 46 \\
8 & HMMS-NH $-\mathrm{Pd}$ & $60 \mathrm{~min}$ & 47 \\
9 & $\mathrm{Pd} / \mathrm{C}$ & $5 \mathrm{~min}$ & This work \\
10 & $\mathrm{Pd} \mathrm{NPs/RGO}$ & $20 \mathrm{~s}$ & This work \\
& & &
\end{tabular}

equal to the 4-NP concentration ratio $\left(C_{t} / C_{0}\right)$. A linear relation between reaction time and $\ln \left(C / C_{0}\right)$ was obtained in the reduction catalyzed with the Pd NPs/RGO nanocomposite (Fig. 10b), and the rate constant of $k$ was computed to be $2.19 \times 10^{-2} \mathrm{~s}^{-1}$.

To illuminate the important benefits and the reliability of the technique of our current research, it was compared with other available methods, and several outcomes for reducing 4NP are presented in Table 1 . The outcomes in Table 1 specify that $\mathrm{Pd} /$ graphene is a more effective catalyst with regard to reaction time, when compared with the earlier reported catalysts. Furthermore, the prepared nanocatalyst was reusable, steady, and showed good catalytic performance.
3.2.2. $\mathrm{MB}$ and $\mathrm{RhB}$ catalytic reduction. In another step, the catalytic reduction of $\mathrm{MB}$, and $\mathrm{RhB}$ dyes with $\mathrm{NaBH}_{4}$ was selected to determine the catalyst performance of the synthesized Pd NPs/RGO. By UV-vis spectroscopy, the progress of the reactions were monitored, as shown in Fig. 11 and 12. As can be observed in the UV-vis spectra, in aqueous medium, MB and RhB display peaks at 663 and $554 \mathrm{~nm}$, respectively.

Fig. 11 and 12 show the absorbance observed by timedependent UV-vis, related to the reduction reactions of the azo dyes. It is obvious that the reduction of the dyes happened immediately, upon adding the Pd NPs/RGO into the diverse dye solutions and the decolorizing was almost finished after 50 and $60 \mathrm{~s}$, for MB and RhB, respectively.

These results suggest that Pd NPs/RGO is the probable cause of the $-\mathrm{N}=\mathrm{N}$ - double bond cleavage in the chromophoric groups in the structures of the azo dyes and thus decolorizes the solutions..$^{48}$ Moreover, the rate constants for the reduction of $\mathrm{RhB}$ and $\mathrm{MB}$ were examined. As the $\mathrm{NaBH}_{4}$ concentration was much more than that of the azo dyes, it can be considered constant over the course of the reaction. Consequently, based on pseudo first order kinetics, $\ln \left(A_{t} / A_{0}\right)=k t$, where $A_{t}$ represents the dye absorbance at time $t, A_{0}$ refers to the dye initial absorbance and the slope $k$ is the obvious reduction rate constant. Best fitting was carried out for the two rate graphs of the azo dyes, and this indicated linear relations between time and rate (Fig. 11b and 12b). As presented in Fig. $11 \mathrm{~b}$ and $12 \mathrm{~b}$, the computed rate constants for reducing $\mathrm{RhB}$ and $\mathrm{MB}$ using the graphene/Pd in the
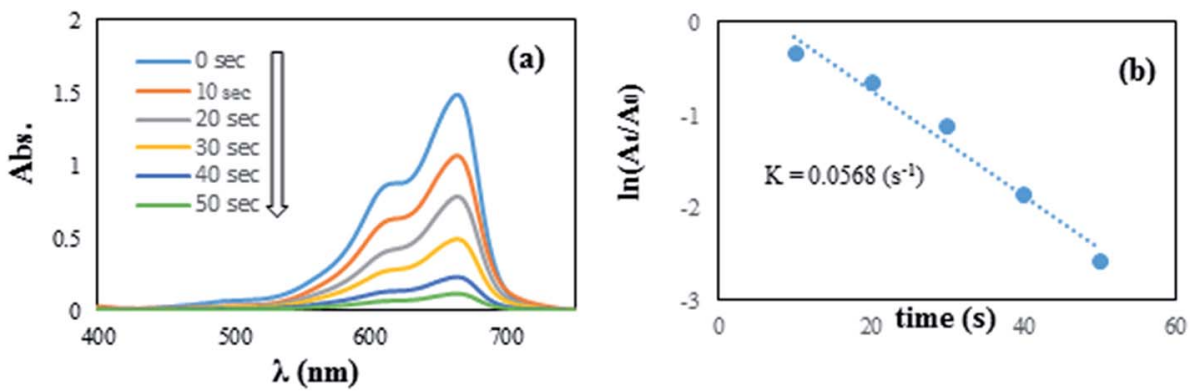

Fig. 11 The reduction of MB in aqueous solution recorded every $10 \mathrm{~s}$ using the Pd NPs/RGO nanocomposite (1 mg) as a catalyst (a) $\ln \left(A_{t} / A_{0}\right)$ versus reaction time for the reduction of $M B(b)$. 

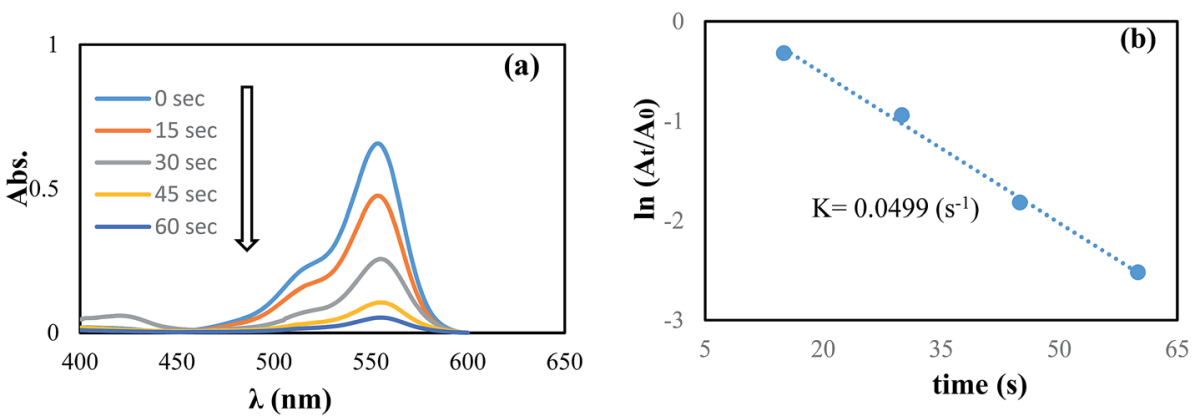

Fig. 12 The reduction of RhB in aqueous solution recorded every $15 \mathrm{~s}$ using the Pd NPs/RGO nanocomposite ( $1 \mathrm{mg})$ as a catalyst (a) $\ln \left(A_{t} / A_{0}\right)$ versus reaction time for the reduction of $\mathrm{RhB}(\mathrm{b})$.

Table 2 Comparison of results for this work with other reported methods in the reduction of $M B$ and $\mathrm{RhB}$

\begin{tabular}{|c|c|c|c|}
\hline Dye & Catalyst & Time & Ref. \\
\hline MB & $\begin{array}{l}\text { Porous } \mathrm{Cu} \\
\text { microspheres }\end{array}$ & $8 \mathrm{~min}$ & 53 \\
\hline MB & $\mathrm{SiNWAs}-\mathrm{Cu}$ & $10 \min$ & 54 \\
\hline MB & $\mathrm{Au} / \mathrm{Fe}_{3} \mathrm{O}_{4} @ \mathrm{C}$ & $10 \mathrm{~min}$ & 55 \\
\hline MB & Ag NPs/seashell & $2.5 \mathrm{~min}$ & 45 \\
\hline MB & $\mathrm{Pd} / \mathrm{C}$ & $6 \mathrm{~min}$ & This work \\
\hline MB & Pd NPs/RGO & $1 \mathrm{~min}$ & This work \\
\hline RhB & $\mathrm{Fe}_{3} \mathrm{O}_{4} @ P A N I @ A u$ & $18 \mathrm{~min}$ & 56 \\
\hline $\mathrm{RhB}$ & $\begin{array}{l}\text { Au-PANI } \\
\text { nanocomposite }\end{array}$ & $15 \mathrm{~min}$ & 57 \\
\hline $\mathrm{RhB}$ & SiNWAs-Cu & $14 \mathrm{~min}$ & 54 \\
\hline RhB & $\mathrm{Pd} / \mathrm{C}$ & $5 \min$ & This work \\
\hline $\mathrm{RhB}$ & Pd NPs/RGO & $50 \mathrm{~s}$ & This work \\
\hline
\end{tabular}

presence of $\mathrm{NaBH}_{4}$ are $4.99 \times 10^{-2} \mathrm{~s}^{-1}$ and $5.68 \times 10^{-2} \mathrm{~s}^{-1}$, respectively.

In our current research study, the outcomes have been compared with a diverse set of reported methods for reduction of different dyes using $\mathrm{NaBH}_{4}$ in Table 2 to illuminate the performance and usability of our green catalyst. The reaction times have been presented in Table 2. According to the results, these values are better for our catalyst, compared to those of

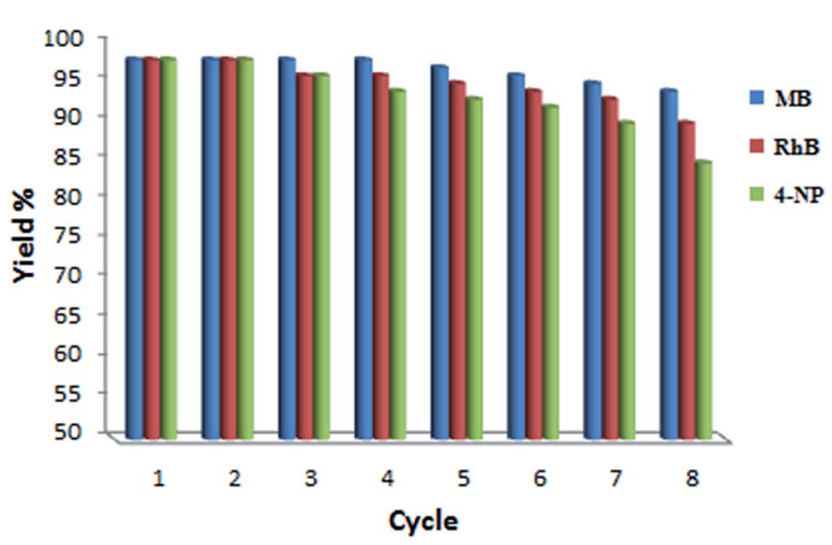

Fig. 13 Reusability of the Pd NPs/RGO nanocatalyst for the reduction of $\mathrm{MB}, \mathrm{RhB}$ and 4-NP in the presence of $\mathrm{NaBH}_{4}$. previous studies of the same catalytic reactions using various nanocatalysts.

The excellent catalytic performance of the Pd NPs/RGO nanocomposite could be achieved due to its small-sized and greatly dispersed Pd NPs. The small size of the Pd NPs produces a great potential difference, and this causes a great reduction rate. Furthermore, a smaller particle size can lead to a greater surface-to-volume ratio with further exposed atoms on the surface that can perform as possible catalytic sites. ${ }^{\mathbf{4 9 - 5 2}}$

\subsection{Recyclability of the catalyst}

Although Pd NPs/RGO presented a great catalytic performance, it is vital to investigate the nanocatalyst for its recycle stability. Consequently, Pd NPs/RGO was isolated and reused for degrading the two dyes, $\mathrm{RhB}$ and $\mathrm{MB}$, for determination of its effectiveness upon recycling. As shown in Fig. 13, the catalytic performance of Pd NPs/RGO was not reduced considerably after 7 cycles for the degradation of both dyes or 4-nitrophenol, and that indicates the great stability of Pd NPs/RGO. The conversion percentage of both $\mathrm{MB}$ and $\mathrm{RhB}$ decreased slightly after the catalyst was recycled seven times.

\section{Conclusions}

A facile approach was developed for the synthesis of Pd NPs/ RGO using an extract of the Rosa canina fruit as a stabilizing and reducing agent. The catalyst was evaluated by UV-vis, FESEM, XRD, WDX, ICP, EDX and TEM. Nanoparticles of Pd NPS/RGO showed significant and durable activity for the catalytic reduction of $4-\mathrm{NP}, \mathrm{RhB}$ and $\mathrm{MB}$ with $\mathrm{NaBH}_{4}$ as the hydrogen source in aqueous medium at room temperature. Furthermore, by centrifugation, the catalyst could be simply separated and successively reapplied for seven cycles, without considerable activity loss, with an approximately complete conversion. This technique has the benefits of an easy preparation of the catalyst, high yields, homogeneous catalysts removal, easy methodology and simple work up.

\section{Conflicts of interest}

There are no conflicts to declare. 


\section{Acknowledgements}

We gratefully acknowledge the Payame Noor University for the support of this work.

\section{References}

1 U. Kurtan, A. Baykal and H. Sozeri, J. Inorg. Organomet. Polym., 2015, 25, 921.

2 R. Saravanan, V. K. Gupta, T. Prakash, V. Narayanan and A. Stephen, J. Mol. Liq., 2013, 178, 88.

3 Z. Han, L. Ren, Z. Cui, C. Chen, H. Pan and J. Chen, Appl. Catal., B, 2012, 126, 298.

4 M. Atarod, M. Nasrollahzadeh and S. M. Sajadi, J. Colloid Interface Sci., 2016, 465, 249.

5 R. Dai, J. Chen, J. Lin, S. Xia, S. Chen and Y. Deng, J. Hazard. Mater., 2009, 170, 141.

6 (a) J.-J. Lv, A.-J. Wang, X. Ma, R.-Y. Xiang, J.-R. Chen and J.-J. Feng, J. Mater. Chem. A, 2015, 3, 290-296; (b) P. Song, L.-L. He, A.-J. Wang, L.-Pi. Mei, S.-X. Zhong, J.-R. Chen and J.-J. Feng, J. Mater. Chem. A, 2015, 3, 5321-5327; (c) L.-P. Mei, R. Wang, P. Song, J.-J. Feng, Z.-G. Wang, J.-R. Chen and A.-J. Wang, New J. Chem., 2016, 40, 23152320; (d) X.-Y. Zhu, Z.-S. Lv, J.-J. Feng, P.-X. Yuan, L. Zhang, J.-R. Chen and A.-J. Wang, J. Colloid Interface Sci., 2018, 516, 355-363; (e) X.-F. Zhang, X.-Y. Zhu, J.-J. Feng and A.-J. Wang, Appl. Surf. Sci., 2018, 428, 798-808; (f) M. Fua, Y. Li, S. Wu, P. Lu, J. Liu and F. Dong, Appl. Surf. Sci., 2011, 258, 1587.

7 B. Naik, S. Hazra, P. Muktesh, V. S. Prasad and N. N. Ghosh, Sci. Adv. Mater., 2011, 3, 1025.

8 (a) H. Veisi, A. Rashtiani and V. Barjasteh, Appl. Organomet. Chem., 2016, 30, 231; (b) H. Veisi, R. Azadbakht, F. Saeidifar and M. R. Abdi, Catal. Lett., 2017, 147, 976; (c) H. Veisi, M. Pirhayati, A. Kakanejadifard, P. Mohammadi, M. R. Abdi, J. Gholami and S. Hemmati, ChemistrySelect, 2018, 3, 1820-1826; (d) H. Veisi, N. Hajimoradian Nasrabadi and P. Mohammadi, Appl. Organomet. Chem., 2016, 30, 890; (e) P. Heidari, R. Cheraghali and H. Veisi, Appl. Organomet. Chem., 2016, 30, 991.

9 H. M. E. Azzazy, M. M. H. Mansour, T. M. Samir and R. Franco, Clin. Chem. Lab. Med., 2012, 50, 193.

10 X. J. Chen, B. L. Sanchez-Gaytan, Z. X. Qian and S. J. Park, Wiley Interdiscip. Rev.: Nanomed. Nanobiotechnol., 2012, 4, 273.

11 Z. Li, X. Wang, G. Wen, S. Shuang, C. Dong, M. C. Paau and M. M. F. Choi, Biosens. Bioelectron., 2011, 26, 4619.

12 P. Ghosh, G. Han, M. De, C. K. Kim and V. M. Rotello, Adv. Drug Delivery Rev., 2008, 60, 1307.

13 R. Kumar Petla, S. Vivekanandhan, M. Misra, A. K. Mohanty and N. Satyanarayana, J. Biomater. Nanobiotechnol., 2012, 3, 14.

14 B. Zahed and H. Hosseini-Monfared, Appl. Surf. Sci., 2015, 328, 536.

15 M. Zargar, A. Abdul Hamid, F. Abu Bakar, M. Nor Shamsudin, K. Shameli, F. Jahanshiri and F. Farahani, Molecules, 2011, 16, 6667.
16 M. Atarod, M. Nasrollahzadeh and S. M. Sajadi, J. Colloid Interface Sci., 2016, 462, 272.

17 M. Nekoeinia, M. Kabiri Dehkordi, M. Kolahdoozan and S. Yousefinejad, Microchem. J., 2016, 129, 236.

18 H. Veisi, S. Taheri and S. Hemmati, Green Chem., 2016, 18, 6337.

19 M. Bagherzadeh, M. Pirmoradian and F. Riahi, Electrochim. Acta, 2014, 115, 573.

20 M. Bagherzadeh, S. Ansari, F. Riahi and A. Farahbakhsh, Int. J. Electrochem., 2013, 2013, 803672.

21 S. Lebaschi, M. Hekmati and H. Veisi, J. Colloid Interface Sci., 2017, 485, 223.

22 S. I. El-Hout, S. M. El-Sheikh, H. M. A. Hassan, F. A. Harraz, I. A. Ibrahim and E. A. El-Sharkawy, Appl. Catal., A, 2015, 503, 176.

23 H. Veisi, S. Hemmati, H. Shirvani and H. Veisi, Appl. Organomet. Chem., 2016, 30, 387.

24 H. Veisi, R. Ghorbani-Vaghei, S. Hemmati, M. Haji Aliani and T. Ozturk, Appl. Organomet. Chem., 2015, 29, 26-32.

25 I. Roman, A. Stanila and S. Stanila, Chem. Cent. J., 2013, 7, 73. 26 F. Demir and M. Ozcan, J. Food Eng., 2001, 47, 333.

27 N. Orhan, M. Aslan, S. Hosbas and O. Deliorman, Pharmacogn. Mag., 2009, 5, 309.

28 C. L. Quave, L. R. W. Plano, T. Pantuso and B. C. Bennet, J. Ethnopharmacol., 2008, 118, 418.

29 S. J. Weiss and N. Engl, J. Med., 1989, 320, 365.

30 G. Schmid, Chem. Rev., 1992, 92, 1709.

31 B. Nakhjavan, M. N. Tahir, F. Natalio, H. Gao, K. Schneider, T. Schladt, I. Ament, R. Branscheid, S. Weber, U. Kolb, C. Sonnichsen, L. M. Schreiber and W. Tremel, J. Mater. Chem., 2011, 21, 8605.

32 B. Khodadadi, M. Bordbar and A. Yeganeh-Faal, J. Sol-Gel Sci. Technol., 2016, 77, 521.

33 M. Suleiman, M. Mousa, A. Hussein, B. Hammouti, T. B. Hadda and I. Warad, J. Mater. Environ. Sci., 2013, 4, 792. 34 G. Zhan, J. Huang, M. Du, I. Abdul-Rauf, Y. Ma and Q. Li, Mater. Lett., 2011, 65, 2989.

35 X. Huang, H. Wu, S. Pu, W. Zhang, X. Liao and B. Shi, Green Chem., 2011, 13, 950.

36 J. A. Dahl, B. L. S. Maddux and J. E. Hutchison, Chem. Rev., 2007, 107, 2228.

37 (a) H. Veisi, S. Najafi and S. Hemmati, Int. J. Biol. Macromol., 2018, 113, 186-194; (b) F. Bonyasi, M. Hekmati and H. Veisi, J. Colloid Interface Sci., 2017, 496, 177; (c) M. Pirhayati, H. Veisi and A. Kakanejadifard, RSC Adv., 2016, 6, 27252; (d) E. Farzad and H. Veisi, J. Ind. Eng. Chem., 2018, 60, 114-124; (e) H. Veisi, A. Sedrpoushan and S. Hemmati, Appl. Organomet. Chem., 2015, 29, 825; $(f)$ B. Maleki, D. Azarifar, R. Ghorbani-Vaghei, H. Veisi, S. F. Hojati, M. Gholizadeh, H. Salehabadi and M. Khodaverdian Moghadam, Monatsh. Chem., 2009, 140, 1485; $(g)$ R. Ghorbani-Vaghei, M. Chegini, H. Veisi and M. KarimiTabar, Tetrahedron Lett., 2009, 50, 1861.

38 N. I. Kovtyukhova, P. J. Ollivier, B. R. Martin, T. E. Mallouk, S. A. Chizhik, E. V. Buzaneva and A. D. Gorchinskiy, Chem. Mater., 1999, 11, 771. 
39 (a) J. F. Moulder, W. F. Stickle, P. E. Sobol and K. D. Bomben. Handbook of X-ray Photoelectron Spectroscopy, Physical Electronics Inc, USA, 1995, pp. 118-119; (b) H. Veisi, S. Najafi and S. Hemmati, Int. J. Biol. Macromol., 2018, 113, 186-194.

40 Y. H. Zhu, J. H. Shen, K. F. Zhou, C. Chen, X. L. Yang and C. Z. Li, J. Phys. Chem. C, 2011, 115, 1614.

41 B. Sreedhar, D. K. Devi and D. Yada, Catal. Commun., 2011, 12, 1009.

42 D. Shah and H. Kaur, J. Mol. Catal. A: Chem., 2014, 381, 70.

43 K. Layek, M. L. Kantam, M. Shirai, D. Nishio-Hamane, T. Sasaki and H. Maheswaran, Green Chem., 2012, 14, 3164.

44 R. J. Kalbasi, A. A. Nourbakhsh and F. Babaknezhad, Catal. Commun., 2011, 12, 955.

45 A. Rostami-Vartooni, M. Nasrollahzadeh and M. Alizadeh, J. Colloid Interface Sci., 2016, 470, 268.

46 A. K. Shil, D. Sharma, N. R. Guha and P. Das, Tetrahedron Lett., 2012, 53, 4858.
47 P. Wang, F. Zhang, Y. Long, M. Xie, R. Li and J. Ma, Catal. Sci. Technol., 2013, 3, 1618.

$48 \mathrm{~N}$. Aljamali, Review in azo compounds and its biological activity, Biochem. Anal. Biochem., 2015, 4, 1000169.

49 P. L. Redmond, A. Hallock and L. E. Brus, Nano Lett., 2005, 5, 131.

50 H. Zhang, X. Li and G. Chen, J. Mater. Chem., 2009, 19, 8223.

51 N. R. Jana and T. Pal, Langmuir, 1999, 15, 3458.

52 W. J. Plieth, J. Phys. Chem., 1982, 86, 3166.

53 Y. Zhang, P. Zhu, L. Chen, G. Li, F. Zhou, D. D. Lu, R. Sun, F. Zhou and C. Wong, J. Mater. Chem. A, 2014, 2, 11966.

54 X. Yang, H. Zhong, Y. Zhu, H. Jiang, J. Shen, J. Huang and C. Li, J. Mater. Chem. A, 2014, 2, 9040.

55 Z. Gan, A. Zhao, M. Zhang, W. Tao, H. Guo, Q. Gao, R. Mao and E. Liu, Dalton Trans., 2013, 42, 8597.

56 S. Xuan, Y. X. J. Wang, J. C. Yu and K. C. F. Leung, Langmuir, 2009, 25, 11835.

57 B. Zhang, B. Zhao, S. Huang, R. Zhang, P. Xu and H. L. Wang, CrystEngComm, 2012, 14, 1542. 